\section{Soloborative Learning: Solo Thinking, Collaborative Tinkering}

\author{
Selçuk Özdemir
}

$\begin{array}{ll}\text { Received: } & 26 \text { September } 2018 \\ \text { Revised: } \quad 03 \text { November } 2018 \\ \text { Accepted: } \quad 09 \text { December } 2018 \\ \text { ISSN: } 1307-9298 \\ \text { Copyright @ IEJEE } \\ \text { www.iejee.com }\end{array}$

DOI: $10.26822 /$ iejee.2019349246

\begin{abstract}
The history of innovation is constructed by solo thinkers and collaborative makers. The word innovation here comprises changes on technology, art and science. This article aims to reflect the way successful inventors, artists and scientists followed to do whatever they succeeded so that the coming generations can learn from predecessors' positive and negative experiences. Thinking and observing as solo may be the first step of an entrepreneur dreamer. Thinking and observation allow her to understand the size and depth of the gap on her knowledge integrity. This understanding process is a kind of challenge annoying and disturbing the entrepreneur dreamer during days and nights and causing his/ her to focus on the subject including examining the existing knowledge and experiences. Successful entrepreneur dreamers are aware of the historical knowledge accumulation on the field they focus on. After an entrepreneur dreamer understands what to do, on the second step, she starts tinkering collaboratively with other people whom the dreamer needs because of their own knowledge, experiences, point of view etc. With the help of others, entrepreneur starts the attempts to fill gap on his/her knowledge. These attempts require series of trial and error. First thinking and focusing on a subject as solo and then taking action and tinkering to realize dreams and thoughts as collaborative may lead us to a new learning design approach. "Soloborative Learning" is a derivative word offering the schools a new way to design learning environments, interactions and learning materials so that learners can construct their own knowledge on an innovative and entrepreneurial ecosystem.
\end{abstract}

Keywords: Soloborative Learning, Asymmetric Learning Design, Coding for Kids

\section{Introduction}

The history of technology, art and science is full of the entrepreneurship stories including both success and failure. Succeeded or failed, all the stories triggered by an entrepreneur dreamer who is not just sitting alone lazily, but standing up to take initiative and risk with patience and determined to collaborate with others. The history of "techne" is formed of various layers constructed by different civilizations in time. From Chinese to Indian, from Ancient Greeks to Islamic Societies and finally to European Countries, during the known history of humanity, many craftsmen and artists contributed to everything we use today in our daily lives. Whatever we use as a techne today is an output of a cumulative knowledge grown out for years. For example, a dream about communication with people living on remote places caused many creative explorations started by smoke and for now ended by cellular phone. Another dream about feeding easily and safely firstly led to the use of spear and finally vertical farming. Actually, a cellular phone is the newest version of communication using smoke and vertical farming in a greenhouse is the newest version of a spear! What happened in time is just a successor who is a visionary added new knowledge and skills to the existing knowledge and skills produced by a predecessor who was a dreamer. It is impossible to find technology or scientific knowledge which is not based on a prior knowledge.

What is the behavioral pattern of a successor entrepreneur dreamer? Are there any pattern of entrepreneur dreamers on how to realize their own dreams and thoughts? When you examine the lives of noted scientists, artists, philosophers or technologists, most of their journey towards success start with childish thoughts about a problem or situation. They observe their own surroundings, then they catch some details unconsciously or consciously. Whatever they catch triggers related and more detailed observations, because the details they caught during observation instigates the gaps and shortage on one's knowledge integrity. Livio (2018; $\mathrm{p}: 71)$ emphasizes that this instigation causes a kind of cognitive itching. The cognitive itch feeling disturbs and pushes the person to fill the gap on his/her knowledge integrity. Thinking and observing as solo on the caught detail may be the first step of an entrepreneur dreamer, because he/she tries to understand the size and depth of the gap on his/her knowledge integrity. This understanding process is a kind of challenge annoying and disturbing the entrepreneur dreamer during days and nights and causing his/her to focus on the subject including examining the existing knowledge and experiences. Successful entrepreneur dreamers are aware of the historical knowledge accumulation on the field they focus on. After an entrepreneur dreamer understands what to do, on the second step, he/she starts tinkering collaboratively with other people whom the dreamer needs because of their own knowledge, experiences, point of view etc. With the help of others, entrepreneur starts the attempts to fill gap on his/her knowledge. These attempts require series of trial and error...., constructing and breaking down and reconstructing and breaking down. First thinking and focusing on a subject as solo and then taking action and tinkering to realize dreams and thoughts as collaborative may lead us to a new learning design approach. "Soloborative Learning" is a derivative word offering the schools a new way to design learning environments, interactions and learning materials so that learners can construct their own knowledge on an innovative and entrepreneurial ecosystem.

\section{Asymmetric Learning Design for Soloboration}

The existing school system, designed due to the needs of the Industrial Revolution, hasn't been responding to the needs of the 21st Century. The Industrial Revolution forced people to do just whatever is required of them. In the Industrial Age, Taylorism and Fordism production models divided all businesses into pieces, and required workers to just focusing on the job they were directed to. The workers were not able to

a,*Correspondence Details: Selçuk Özdemir, Gazi University, Faculty of Education, Department of Computer and Instructional Technologies Education, Ankara, Turkey. E-mail: selcukozdemir@gmail.com

(c) 2018 Published by T\& K Academic. This is an open access article under the CC BY- NC- ND license. (https://creativecommons.org/licenses/by/4.0/) 
see the whole picture of production, but they were only aware of whatever was dictated to them. The classical schooling was structured similar to industrial organizations. All the disciplines were divided into courses, and all courses divided into chapters, all chapters were divided into goals and learning outcomes. Each single course was positioned as symmetric and parallel to other courses without touching each other. All the behaviors a student should gain were defined exactly by educators. If a student showed average learning outcomes especially in multiple choice exams, he/she was considered to be successful. On the other hand, the students failed if they were unable to find the correct answer among the given choices $A, B, C, D$ or $E$.

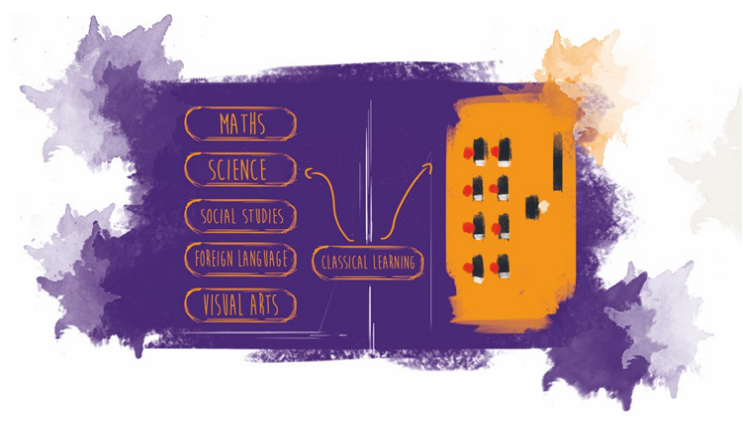

Figure 1. Classical learning

Why does classic schooling system not work to respond to the 21st Century's needs? The reason is hidden in the "changing concept of labor". The 21st century creates its own machines to do average work and to select correct answer among the given choices. The changing labor will force the new generations to find their own $\mathrm{F}$ choice, $\mathrm{H}$ choice or Z choice. In short, today's primary and secondary school students have to be innovative, creative, visionaries, entrepreneurs and collaborators to exceed average skills (Rose, 2016; Rifkin, 2011), otherwise, smart machines and software will already do whatever their parents were doing in the past.

To be more creative, innovative, collaborative and entrepreneurs, the students need to face more ill-defined problems and to find solutions using information from different disciplines such as Math, Science and Humanities etc. in the school environment. Ill-defined problems can be defined as "problem in problem" (Morin, 1999; p: 11). Edgar Morin says that in real life situations, the new solutions for problems may cause new problems and schools should teach students how to solve problems in problems. As long as you find solutions, you may face new problems caused by your solution. Moreover, solutions for problems in real life requires use of more than one discipline. When you decide to produce a new car, just mechanical engineering is not enough, you will need visual artists, masters on ergonomics, computer programmers, and many more skills and knowledge from different disciplines. The students should practice on how to use more than one discipline at the same time for the same problem situation.

Goethe says that he hates everything that only instructs him without augmenting or directly invigorating his activity (Nietzsche, 1996). Learning process should increase children's' effectiveness and add values directly to their lives. To prepare students so that they can solve "problems in problem" and handle information from more than one discipline, the learning process should better start with an entrepreneurial problem, because entrepreneurial problems:

-are formed from vague and ill-defined ingredients causing problems in problems -need various information and skills forcing students to use more than one discipline,

- need more labor and various points of view to complete the task requiring collaboration, creative thinking and critical thinking,

-require patience and persistence to solve the problems in problems.

The entrepreneurial problem can be designed by a group of teachers from different disciplines such as math, physics, chemistry, geography, language, computer sciences etc. or determined by student(s) by the help of teacher(s). The entrepreneurial problem should be complex enough to confuse the students, because human beings are not curious about the things which they know well or do not know anything about (Livio 2018; p:71).

After the presentation of entrepreneurial problem, each student starts to examine, analyze and think of the problem as solo or in small groups sharing with each other. After the causes of the problem are listed, the students should start to collaborate with other students and teachers to find out the optimum solution and to realize the offered solution. This collaboration process is asymmetric, because each offered solution may require information and skills from different disciplines. The information and skills quantities needed from different disciplines can also be different from solution to solution. While a group of students in collaboration may use $25 \%$ math, $10 \%$ physics, 50\% visual arts and 15\% ergonomy, another group of students focus on mostly math and physics and biology to solve the same problems. In an asymmetric learning environment, even teachers cannot guess which disciplines students will use and the weight of each discipline on the solution, because students will not select a choice among the given ones, but they will create their own choices from which the teachers may learn something new.

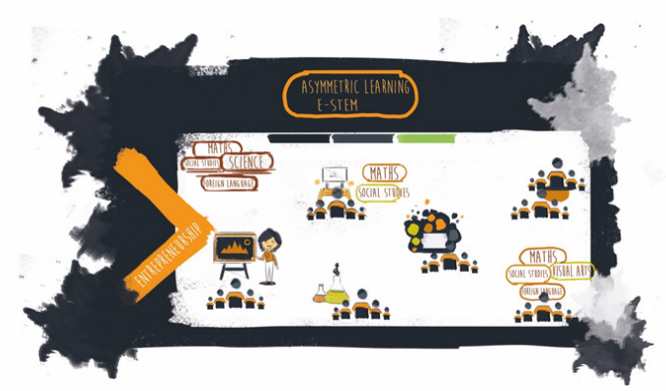

Figure 2. Asymmetric learning

The most important point for an asymmetric learning environment is that, all the disciplines are just sources and instruments for the solution of entrepreneurial problem. The learning environment designed as a workshop should facilitate the use of information, tools and skills from math, science, digital/non digital technologies, social science and humanities. During the development of a solution, students may try their thoughts many times. As long as students can use sources and instruments easily, they will be able to develop their solutions even compared to solutions they thought at the beginning of the study.

\section{The Miracle of Ctrl+Z for Soloboration}

The history of "techne" is the history of thinking and tinkering. The history of science and technology was written by the people who were patient enough to repeat the experiments many times. For thousands of years, all the entrepreneurs in the field of science, technology, politics, art 
etc. have tried, failed, learnt, and tried again in their own limits of time, infrastructure and finance. They sometimes learnt from their own experiences and sometimes from others' experiences as Einstein was saying "My best teacher was Newton. Without his findings, I could not have been able to find out anything." Somehow, each new knowledge is constructed based on the existing information and experiences. Here, what I want to emphasize is that even computer software development is one of the youngest and newest fields, today it is the most important technological and scientific field even for all other technological, scientific, artistic etc. fields because of its "forgiving" aspect. Da Vinci says that "wisdom is the child of experience." Since on any other field no one has unlimited right to make mistakes, the accumulation of experiences and knowledge creation is limited compared to software development. Trial and error method on medicine, engineering, farming, any field except for software development is very expensive and risky. On the other hand, you can try any dream you have on computer programming process, because you know that when you make a mistake, just pressing "Ctrl+Z" keys is enough "to be forgiven." These keys may be the biggest reason we have crazy software on our computers, tablets, PCs, smart phones, cars etc.

Nowadays, computer coding courses for primary and secondary school students are very popular around the world. It seems that coding will be one of the very important basic skill for the coming generations. Computer coding skills may be a kind of new paper and pencil for them to articulate and create what they think. John Dewey, Maria Montessori, Ivan Pavlov, Frederic Skinner, Jean Piaget, all education philosophers having different theories on pedagogy pointed out the same aspect of learning: practice. Practice was the basic and first condition of learning even before classical schools. Today, computer coding ability is a very cheap, patient and easy practice tool for learning starting from primary schools. Similar to professional software developers, children can test and practice giving directions to machines (computers and similar devices) on whatever they think and want to do. Computer coding ability and its $C t r l+Z$ aspect enable students to embody their dreams and the way they think. Here, the childhood of Elon Musk, Steve Jobs and Bill Gates are important examples. Elon Musk says (Vance, 2015; ) that when he learnt computer coding himself at 10, he realized that he could do anything giving directions to computers. Interestingly, his first dream was the driverless cars he presented to us today!

To conclude, as a Turkish academician and entrepreneur, 5 years ago, I developed an asymmetric learning design for primary and secondary schools and today about 100.000 students on 350 schools use this platform in 70 cities in Turkey. This new learning design Includes:

-15.000 online content on coding, 3D design, circuit design, entrepreneurship etc.,

- Face to face trainings for teachers from different disciplines,

- A modular curriculum adaptable for the needs of each school.

- Rubrics to evaluate products and processes,

- The digital and non-digital materials for workshops,

- Tournaments and fairs so that students could show whatever they learnt and whatever they developed.
Rewarded three times by national institutions, this initiative aims to offer schools an alternative way of designing the 21 st century learning ecosystem, because today's children will face a very different social and professional life compared to their parents'. So, forcing them to be educated in the schools designed 200 years ago may cause great social problem $\mathrm{s}$ when they try to find jobs starting from 2030s. So, it's time to act before it can be late to use "Ctrl+Z"

\section{References}

Livio, M. (2017). Why? What makes us curious? Simon \& Schuster Publishing.

Morin, E. (1999). Seven Complex lessons for the future. UNESCO Publishing.

Nietzsche, F. (1996). Tarih üzerine. İstanbul: Say Publishing. İstanbul.

Rifkin, J. (2011). The third industrial revolution: How lateral power is transforming energy, the economy, and the world. St. Martin's Press.

Rose, T. (2016). The end of average. New York: HarperCollins Publishing.

Vance, A. (2015). Elon Musk: Tesla, SpaceX, and the quest for a fantastic future. Ecco Publishing. 